\title{
Evaluation of root resorption after comprehensive orthodontic treatment using cone beam computed tomography (CBCT): a meta-analysis
}

Yaqi Deng, Yannan Sun and Tianmin Xu*

\begin{abstract}
Background: Orthodontic treatment can result in root resorption (RR). Traditional two-dimensional (2D) data exhibit magnification, deformation and positioning problems. Cone beam computed tomography (CBCT) contains more accurate three-dimensional (3D) information. This study identified and qualified the extent and location of root resorption using cone beam computed tomography (CBCT) after comprehensive orthodontic treatment.

Methods: Studies comparing the RR before and after comprehensive orthodontic treatment using CBCT were identified using electronic searches of databases, including Cochrane, PubMed, EMBASE, China National Knowledge Infrastructure (CNKI) and Web of Science, and manual searches in relevant journals and the reference lists of the included studies until Oct 25, 2017. The extraction of data and the risk of bias evaluation were conducted by two investigators independently. The methodological quality of the included studies was assessed using the methodological index for non-randomized studies (MINORS). Studies that reported the length and volume of teeth were used for quantitative analyses.

Results: Twelve studies were included in the meta-analysis. The length of all teeth after intervention was significantly shorter than that before treatment $(M D=0.80,95 \% \mathrm{Cl} 0.56,1.03, P<0.00001)$. The sequence of RR from heaviest to lightest was maxillary lateral incisors, maxillary central incisors, mandibular anterior teeth, and maxillary canines. Studies were divided into two subgroups based on the use of tooth extraction. Root shortening after treatment was observed in both groups, and extraction caused more root resorption than was observed in the non-extraction group.

Conclusions: There were different degrees of root resorption after orthodontics, but it was clinically acceptable. Root resorption established in CBCT research was less serious and more accurate than that observed in the twodimensional research. Current evidence suggests that root length and volume were reduced after orthodontic treatment. The order of the amount of RR was maxillary lateral incisors, maxillary central incisors and mandibular anterior teeth. Most of the articles were complicated by different confounding factors. Therefore, more high-quality clinical trials are needed to determine the risk factors of root resorption and optimal protocols for treatment and to draw more reliable conclusions.
\end{abstract}

Keywords: Root resorption, Cone beam computed tomography, Orthodontics, Meta-analysis

\footnotetext{
* Correspondence: tmxuortho@163.com

Department of Orthodontics, Peking University School and Hospital of

Stomatology, Beijing 100081, People's Republic of China
}

(c) The Author(s). 2018 Open Access This article is distributed under the terms of the Creative Commons Attribution 4.0 International License (http://creativecommons.org/licenses/by/4.0/), which permits unrestricted use, distribution, and reproduction in any medium, provided you give appropriate credit to the original author(s) and the source, provide a link to the Creative Commons license, and indicate if changes were made. The Creative Commons Public Domain Dedication waiver (http://creativecommons.org/publicdomain/zero/1.0/) applies to the data made available in this article, unless otherwise stated. 


\section{Background}

External apical root resorption (EARR) is a reduction in root structure involving the apices, and it is a common phenomenon of orthodontic treatment in the modern world [1]. Most resorption is clinically insignificant, but severe root resorption threatens tooth longevity and causes tooth mobility or loss [2]. With improvements in orthodontic techniques and increased patient expectations, orthodontists need to be aware of EARR [3].

The prevalence of EARR is high, and the factors affecting it are complex and multiple, including internal and external factors. Internal factors are patient factors that include genetics, age at the start of treatment, gender, nutrition, root morphology, alveolar bone density, type of malocclusion, and so on [4-6]. External factors are primarily caused by orthodontic treatment, such as the type of appliance, treatment technique, continuous or intermittent force, force magnitude and direction, duration of the applied force, premolar extractions, tooth distance and root movement are risk factors for EARR [7-9]. The causes and mechanisms of resorption are not completely clear.

Different aspects of tooth resorption, including prevalence and degree, were investigated using conventional radiographs. Conventional radiographs include periapical film, panoramic radiograph, and lateral cephalometric images. Image distortion and magnification are common characteristics of panoramic radiography, also known as non-positioning radiographs, and this technique imprecisely measures cephalometric points $[10,11]$. The disadvantages of this approach include confounded images caused by superimposed anatomic structures and a lack of right- and left-side information [12].

However, root resorption occurs 3-dimensionally, and $2 \mathrm{D}$ images cannot detect root resorption on lingual or buccal surfaces nor measure the volume of root loss. Therefore, quantification of treatment outcome using $2 \mathrm{D}$ images raised some criticism because of its reliability.

CBCT is an effective imaging method for the diagnosis of orthodontic root resorption using a 1: 1 ratio for reconstruction with no amplification error [13]. CBCT clearly shows the root structure, which results in more accurate qualitative judgment of orthodontic root resorption [14, 15]. CBCT images enhance cross-section research in three dimensions because the images may be observed at any angle using $3 \mathrm{D}$ reconstruction. Therefore, studies on RR using CBCT demonstrated improved accuracy and sensitivity in comparison with those using $2 \mathrm{D}$ data [16]. CBCT data contain equal image information of the right and left sides with no interference due to image overlap. Wang demonstrated that CBCT accurately measured tooth and root resorption volumes, and it was a more accurate and reliable $3 \mathrm{D}$ measuring method for EARR investigation [17]. Another significant advantage of CBCT in root resorption studies is that it could be used in vivo, compared with Micro CT.

Weltman et al. [4] and Roscoe et al. [18] systematically reviewed root resorption associated with orthodontic treatment based on 2D images, but they did not do quantitative synthesis. There are no systematic reviews of root resorption associated with orthodontic treatment based on CBCT data, which is a more accurate and scientific method [19]. Therefore, it is necessary to integrate the data and conclusions of these trials. The purpose of this article is to report the results of a rigorous systematic review of the scientific literature relating to EARR in patients with fixed orthodontic appliances using the most accurate imaging information, CBCT.

\section{Methods}

This meta-analysis was performed in accordance with the guidelines of the Preferred Reporting Items for Systematic Reviews and Meta Analyses (PRISMA) checklist and PRISMA harm checklist items.

\section{Types of studies}

Study design: Randomized and non-randomized controlled trials, clinical trials, and prospective and retrospective reports were included. Longitudinal studies that observed root changes at different time points of treatment (before and after orthodontic treatment) were included. Self-controlled studies were included. Case reports, case series studies, descriptive studies, opinion articles and reviews were not included.

\section{Types of participants}

We included studies of orthodontic patients with no restrictions in the characteristics of occlusion, age or gender, and with available pre-and post-operative CBCT data. Patients with periodontitis were excluded. Pregnant patients and patients with systemic diseases, syndromes, pathologies, or history of root resorption were excluded.

\section{Types of interventions}

For comprehensive orthodontic treatment, patients in permanent dentition with fixed appliances, such as brackets and bands were included. Patients with different wire techniques and orthognathic surgery patients with pre-operative orthodontics with extraction treatment (bicuspid extraction on the upper and/or lower arch) or non-extraction were also included. Patients with local orthodontic treatment or stage treatment were excluded. 


\section{Types of outcome measures}

Primary outcomes: Root resorption was evaluated using CBCT after orthodontic treatment. The primary outcomes were tooth/root length and tooth/root volume.

The PICOS format and null hypothesis are shown in Table 1.

\section{Search methods for study identification}

For the identification of studies to include or consider for this review, we developed detailed search strategies for each database searched. These strategies were based on the search strategy developed for MEDLINE but revised appropriately for each database. We searched the following databases: the CNKI database, the Cochrane Library, Web of Science, PubMed and EMBASE (to October 2017). We used no language or date restrictions in the searches of the electronic databases. The key words used to screen the databases are shown in Table 2. Citations of the remaining studies were examined to identify publications not located in the MEDLINE database. We contacted the authors of randomized controlled trials to identify any unpublished trials.

\section{Data collection and analysis}

Selection of studies The studies were screened, selected, and evaluated by two independent authors. Titles and abstracts were examined, and duplicate studies were eliminated. Full texts were obtained when the abstracts did not provide sufficient information. In the second phase of selection, eligibility criteria were used on the full articles. Any discrepancies in the inclusion of articles between reviewers were addressed via discussion until consensus was reached. Disagreements were resolved via discussion and consultation with a third author.

Data extraction and management Two independent authors (Deng and Sun) abstracted study data and evaluated data quality. Disagreements were adjudicated via consensus with a third reviewer $(\mathrm{Xu})$. Data included study design (randomization procedure, blinding and

Table 1 PICOS format and null hypothesis

\begin{tabular}{ll}
\hline PICOS format & \\
\hline Population & Patients with orthodontics \\
Intervention & Comprehensive orthodontics; not local orthodontics \\
Comparison & $\begin{array}{l}\text { Before and after treatment } \\
\text { Outcome }\end{array}$ \\
$\begin{array}{l}\text { Root resorption evaluated as tooth/root length and } \\
\text { volume assessed using radiographic imaging CBCT } \\
\text { Null hypotheses }\end{array}$ & $\begin{array}{l}\text { There is no difference in the incidence and severity of } \\
\text { root resorption before and after comprehensive } \\
\text { orthodontic treatment. }\end{array}$ \\
\hline
\end{tabular}

assessment endpoints) and patient characteristics (number, age, author, gender, indication, published years, and orthodontic site). When the data could not be culled from the article, we contacted the authors.

\section{Methodological quality assessment}

Two independent authors (Deng and Sun) assessed the quality of each study included in the meta-analysis using Methodological Index for Non-randomized Studies (MINORS). Evaluations were compared, and any inconsistencies between the review authors were discussed and resolved. For the self-controlled studies, the MINORS scores ranged from 9 to 15 out of a possible score of 16 (Table 3). There were no clear and consistent inclusion criteria for the included studies, but they were identified as moderate scientific evidence considering their prospective properties and the consecutive inclusion of participants.

\section{Statistical analysis}

Two authors independently screened the eligible studies, assessed the risk of bias in the trials and extracted data. The following outcomes of interest were recorded: tooth/root length and tooth/root volume. We calculated the mean differences (MD) with 95\% confidence intervals (CI) for continuous data and risk ratios (RR) with 95\% CI for dichotomous outcomes. Heterogeneity was tested using Cochrane's Q-test. $I^{2}>50 \%$ was defined to indicate significant heterogeneity $\left(I^{2}\right.$-value superior to 25,50 and $75 \%$ corresponding to low, medium and high heterogeneity, respectively). Meta-analyses were performed using Review Manager 5.3 (Nordic Cochrane Centre, Copenhagen, Denmark). If the studies used similar participants and similar interventions, the fixed-effect model was used; if there was potential heterogeneity among studies, we preferred to use random-effects models. If sufficient data were available, we performed the following subgroup analyses: position of tooth; different intervention; extraction group and non-extraction group. If there were insufficient clinical trials for specific interventions or insufficient data for extraction, we qualitatively described the results. We then evaluated the influence of each subgroup on heterogeneity using forest plot analysis. Publication bias was assessed using funnel plot analysis.

\section{Results \\ Description of studies Search results}

A total of 473 studies were obtained from the five databases. All abstracts were entered into the software Endnote (X8). The software screened for duplication, and 380 studies were retrieved. All the remaining studies were screened by the authors. A total of 206 abstracts 
Table 2 Search results

\begin{tabular}{lll}
\hline Data base & Search strategy & Numbers \\
\hline CNKI & $\begin{array}{l}\text { Subject = root resorption AND Subject = orthodontic AND Subject = CBCT } \\
\text { (accurate match) }\end{array}$ \\
& $\begin{array}{l}\text { Root resorption: ti, ab kw and Orthodontics: ti, ab, kw and cone beam } \\
\text { Computed tomography: ti, ab, kw }\end{array}$ \\
& TS $=(($ root resorption) AND orthodontics AND (CBCT OR (Cone Beam \\
Web of Science & Computed Tomography))) \\
& (Cone Beam Computed Tomography))) (root resorption) AND (root resorption) AND \\
PubMed & (orthodontics OR orthodontic) AND (CBCT OR (Cone Beam Computed Tomography)) \\
& 'tooth disease' AND 'orthodontics' AND 'cone beam computed tomography' \\
EMBASE & AND [1-1-1966]/sd NOT [30-9-2017]/sd AND [1966-2017]/py \\
\hline
\end{tabular}

were retrieved after excluding reviews, case reports, animal research and articles that did not conform to the research purpose. A total of 165 studies were excluded after full-text analysis for the following reasons: a. no results of $\mathrm{CBCT}$ examination; b. no assessment of root resorption; and c. local or stage treatment. Among 41 studies, 12 studies were analyzed quantitatively. The search results are presented in Table 2 and the flowchart of the literature search is presented in Fig. 1. Twelve studies were included in this review: Sun et al. [20]; Castro et al. [2]; Ahn et al. [13]; Wang et al. [21]; Wang et al. [22]; Qiao et al. [23]; Castro et al. [24]; Xu [25]; Wang et al. [26]; Oliveira et al. [27]; Ni et al. [28]; Zhang et al. [29].

\section{Study characteristics}

Study characteristics were summarized in Table 4.

Table 3 Methodological index for non-randomized studies (MINORS)

\begin{tabular}{|c|c|c|c|c|c|c|c|c|c|c|}
\hline $\begin{array}{c}\text { MINORS } \\
\text { score Author }\end{array}$ & Year & 1 & 2 & 3 & 4 & 5 & 6 & 7 & 8 & Total \\
\hline Sun et al.[20] & 2012 & & & & & & & & & 13 \\
\hline Castro et al.[2] & 2013 & & & & & & & & & 15 \\
\hline Ahn et al.[13] & 2013 & & & & & & & & & 11 \\
\hline $\begin{array}{l}\text { Wang et } \\
a l .[21]\end{array}$ & 2013 & & & & & & & & & 13 \\
\hline $\begin{array}{l}\text { Wang et } \\
\text { al.[22] }\end{array}$ & 2014 & & & & & & & & & 12 \\
\hline Qiao et al.[23] & 2014 & & & & & & & & & 9 \\
\hline $\begin{array}{c}\text { Castro et } \\
\text { al.[24] }\end{array}$ & 2015 & & & & & & & & & 12 \\
\hline $\mathrm{Xu}$ [25] & 2015 & & & & & & & & & 11 \\
\hline $\begin{array}{l}\text { Wang et } \\
\text { al.[26] }\end{array}$ & 2015 & & & & & & & & & 13 \\
\hline $\begin{array}{c}\text { Oliveira et } \\
\text { al.[27] }\end{array}$ & 2016 & & & & & & & & & 12 \\
\hline Ni et al.[28] & 2016 & & & & & & & & & 11 \\
\hline $\begin{array}{c}\text { Zhang et } \\
\text { al.[29] }\end{array}$ & 2016 & & & & & & & & & 10 \\
\hline
\end{tabular}

Items 1-12 represent: 1, a clearly stated aim; 2 , inclusion of consecutive patients; 3 , prospective collection of data; 4 , endpoints appropriate to the aim of the study; 5 , unbiased assessment of the study endpoint; 6 , follow-up period appropriate to the aim of the study; and 7, loss to follow-up less than $5 \%$; 8 , prospective calculation of the study size. An item scored 0 means not mentioned, 1 means reported but inadequate, and 2 means reported and adequate. The total score was 16 for self-controlled studies. Use red for 0 , yellow for 1 yellow and green for 2 


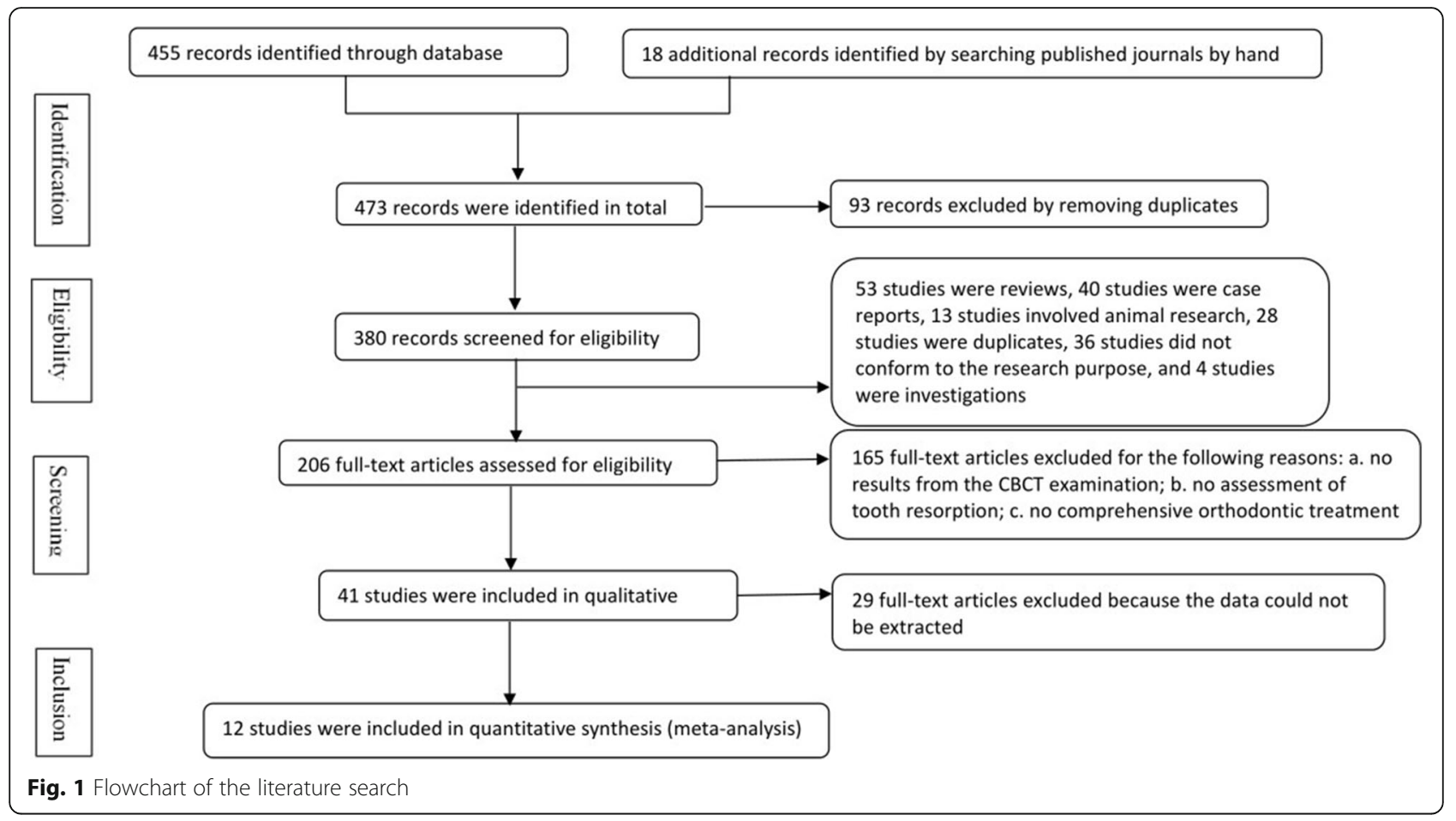

Characteristics of the participants A total of 247 participants were investigated and provided 1039 teeth in the 12 studies. The mean age of the participants ranged from 12.8 to 26.62 years, and both genders were included. Three studies [2, 24, 29] were based on teenagers, and the other studies included adults. Participants in four studies [20-22, 26] had skeletal malocclusion that was more serious than other studies, which may be the risk of root resorption.

Characteristics of the interventions All studies included comprehensive orthodontics, not local treatment, and the duration was between pre-treatment and post-treatment. Pre-operative decompensation of orthognathic surgery was also included. However, this type of intervention is different than normal treatment and may be one source of heterogeneity.

Characteristics of the outcomes Tooth length measurement method was primarily based on CBCT data. Tooth length was the distance from the apex to incisal edge or cusp. The volume index measurement method was performed using software for root reconstruction to calculate tooth volume before and after treatment. There was little methodological difference between the studies, and a low measurement bias could be considered.

Risk of bias in included studies The main bias was the implementation bias, which occurred in the process of intervention. Multiple factors of root resorption were also interfering factors. Three articles $[2,20,26]$ exhibited report bias.

\section{Effects of interventions \\ Primary results \\ Tooth length-total teeth}

Ten studies reported changes in tooth length using CBCT. Meta-analysis revealed medium heterogeneity $\left(\mathrm{I}^{2}=33 \%\right)$, and a random effect model was used. Posttreatment was comparable to pre-treatment $(\mathrm{MD}=0.80$, 95\% CI $0.56,1.03, \quad P<0.00001)$. The meta-analysis results are shown in Fig. 2. The funnel plot was more symmetrical, which indicates a small publication bias (Fig. 3). The source of heterogeneity may lie in the method of measurement. Ahn et al. and Wang et al.'s studies $[13,21,22]$ measured the root length, which was the distance from the apex to the enamel dentin boundary, but other studies measured the tooth length as the distance from the cusp or incisal edge to apex.

\section{Tooth length-maxillary central incisor}

Seven studies reported changes of tooth length in maxillary central incisors using CBCT. Tooth length was significantly reduced after orthodontic treatment $(\mathrm{MD}=0.84,95 \% \mathrm{CI}$ $0.56,1.12, P<0.00001)$. The meta-analysis results are shown in Fig. 4. 


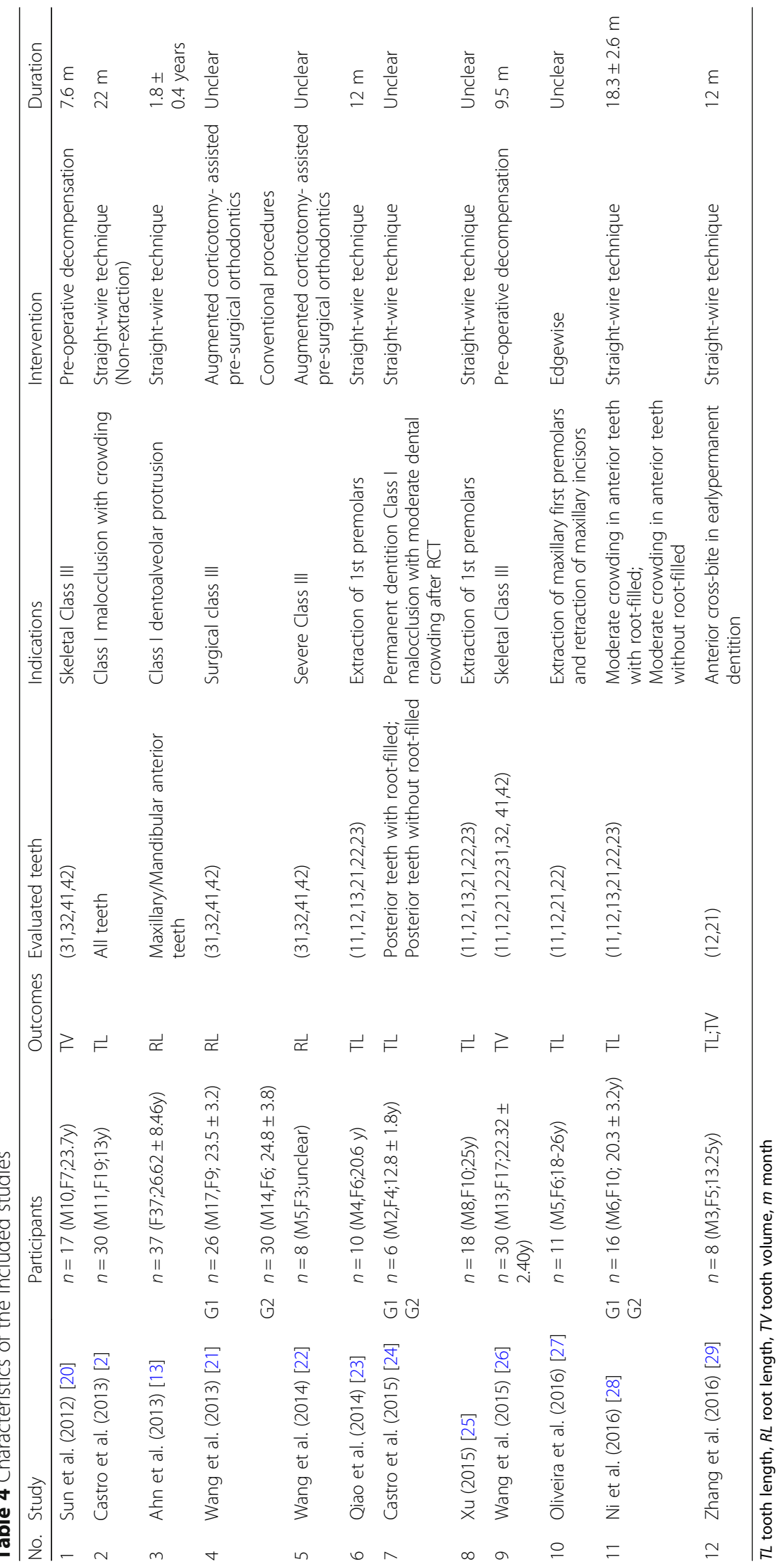




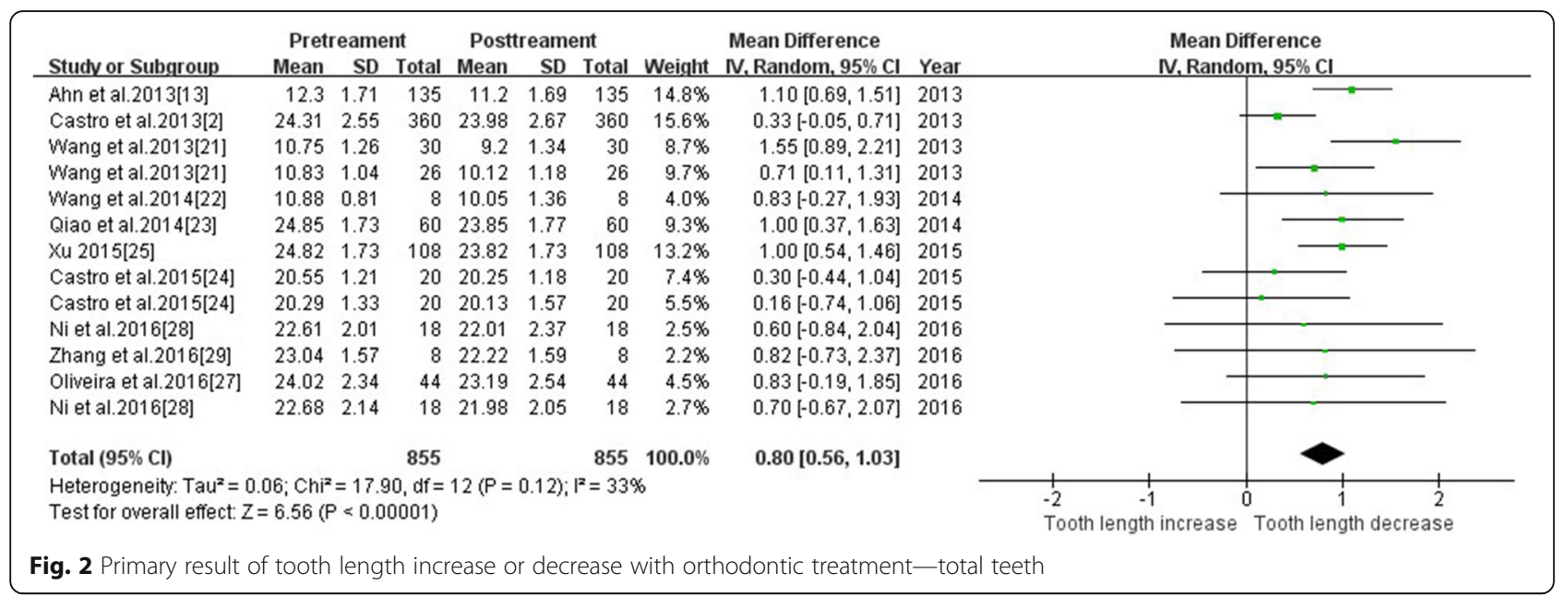

\section{Tooth length-maxillary lateral incisor}

Six studies reported changes of tooth length in maxillary lateral incisors using CBCT. Tooth length of maxillary lateral incisors was significantly reduced after treatment $(\mathrm{MD}=0.90, \quad 95 \% \quad \mathrm{CI} \quad 0.58, \quad 1.22, \quad P<0.00001)$. The meta-analysis results are shown in Fig. 5.

\section{Tooth length-maxillary canine}

Five studies reported changes in maxillary canine. Meta-analysis revealed low heterogeneity $\left(\mathrm{I}^{2}=19 \%\right)$, and a fixed-effect model was used. The tooth length was significantly shorter after treatment $(\mathrm{MD}=0.68,95 \% \mathrm{CI}$ $0.37,1.00, P<0.00001)$. The meta-analysis results are shown in Fig. 6.

\section{Tooth length - mandibular anterior teeth}

Three studies reported changes of tooth length in mandibular anterior teeth using CBCT. Meta-analysis revealed high heterogeneity $\left(\mathrm{I}^{2}=63 \%\right)$, and a random-effect model was used. Sensitivity tests were performed after the removal of different study groups in Wang et al. [21], and the heterogeneity was reduced to $0 \%$. Post-treatment was comparable to pre-treatment $(\mathrm{MD}=0.53 \quad 95 \% \quad \mathrm{CI} \quad 0.16, \quad 0.90, \quad P<0.00001)$. The meta-analysis results are shown in Figs. 7 and 8.

\section{Tooth length-tooth extraction \& non-tooth extraction}

The study was divided into two subgroups, tooth extraction and non-extraction, based on the orthodontic

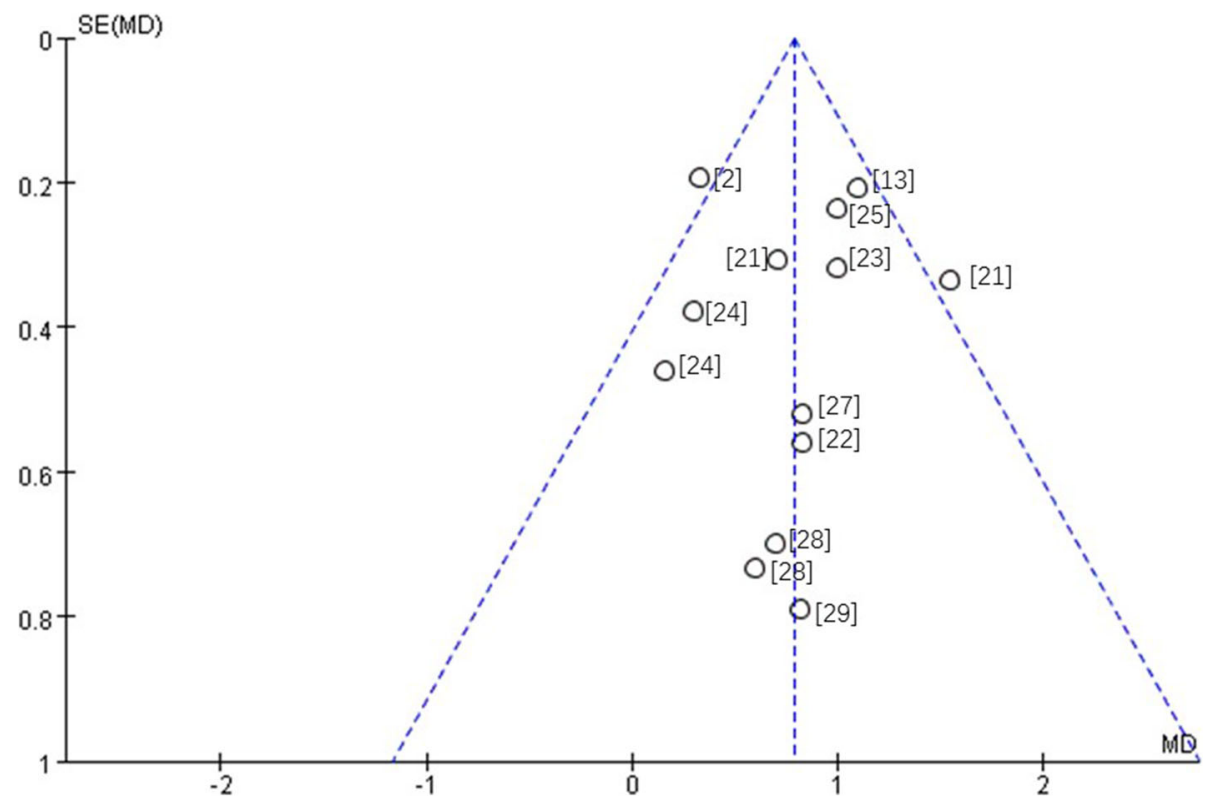

Fig. 3 Funnel plot—root resorption in total teeth. Included studies: Castro et al. [2]; Ahn et al. [13]; Wang et al. [21]; Wang et al. [22]; Qiao et al. [23]; Castro et al. [24]; Xu [25]; Oliveira et al. [27]; Ni et al. [28]; Zhang et al. [29] 


\begin{tabular}{|c|c|c|c|c|c|c|c|c|c|c|c|}
\hline \multirow[b]{2}{*}{ Study or Subgroup } & \multicolumn{3}{|c|}{ Pretreament } & \multicolumn{3}{|c|}{ Posttreament } & \multicolumn{3}{|c|}{ Mean Difference } & \multirow{2}{*}{\multicolumn{2}{|c|}{$\begin{array}{l}\text { Mean Difference } \\
\text { N. Fixed, } 95 \% \mathrm{Cl}\end{array}$}} \\
\hline & Mean & SD & Total & Mean & SD & Total & Weight & IV. Fixed, $95 \% \mathrm{Cl}$ & Year & & \\
\hline Castro et al.2013[2] & 24.85 & 1.73 & 60 & 24.39 & 1.75 & 60 & $20.2 \%$ & $0.46[-0.16,1.08]$ & 2013 & & \\
\hline Ahn et al. $2013[13]$ & 12.33 & 1.44 & 66 & 11.26 & 1.52 & 66 & $30.7 \%$ & $1.07[0.56,1.58]$ & 2013 & & —— \\
\hline Qiao et al.2014[23] & 24.81 & 1.49 & 20 & 23.84 & 1.49 & 20 & $9.2 \%$ & $0.97[0.05,1.89]$ & 2014 & & \\
\hline Xu 2015[25] & 24.76 & 1.5 & 36 & 23.79 & 1.39 & 36 & $17.5 \%$ & $0.97[0.30,1.64]$ & 2015 & & $\longrightarrow$ \\
\hline Oliveira et al.2016[27] & 25.03 & 2 & 22 & 24.23 & 2.31 & 22 & $4.8 \%$ & $0.80[-0.48,2.08]$ & 2016 & & \\
\hline Zhang et al.2016[29] & 23.04 & 1.57 & 8 & 22.22 & 1.59 & 8 & $3.3 \%$ & $0.82[-0.73,2.37]$ & 2016 & & \\
\hline Ni et al.2016[28] & 22.59 & 1.16 & 8 & 21.87 & 0.83 & 8 & $8.0 \%$ & $0.72[-0.27,1.71]$ & 2016 & - & \\
\hline Ni et al.2016[28] & 22.39 & 1.05 & 8 & 21.81 & 1.21 & 8 & $6.4 \%$ & $0.58[-0.53,1.69]$ & 2016 & & \\
\hline Total $(95 \% \mathrm{Cl})$ & & & 228 & & & 228 & $100.0 \%$ & $0.84[0.56,1.12]$ & & & \\
\hline $\begin{array}{l}\text { Heterogeneity: } \mathrm{Ch}^{2}=2 \text {. } \\
\text { Test for overall effect: } Z\end{array}$ & $\begin{array}{l}72, \mathrm{df}= \\
=5.88(\mathrm{P}\end{array}$ & $\begin{array}{l}P(P= \\
P<0.0\end{array}$ & $\begin{array}{l}0.91) ;\left.\right|^{2} \\
0001)\end{array}$ & $=0 \%$ & & & & & & $\begin{array}{cc}1 & 1 \\
-2 & -1 \\
\text { Tooth length increase }\end{array}$ & $\begin{array}{ccc} & 1 & 2 \\
\text { Tooth length decrease }\end{array}$ \\
\hline
\end{tabular}

approach. The following heterogeneity test results were demonstrated: $p=0.96$ and $0.12, \mathrm{I}^{2}$ was 0 and $40 \%$, respectively; the two subgroups combined together $p=$ $0.18, \mathrm{I}^{2}$ was $28 \%$. Subgroup analysis demonstrated $\mathrm{CHI}^{2}$ $=1.10, P=0.29$, and subgroup differences were not statistically significant. Therefore, we speculated whether extraction or not was less affected to heterogeneity. The heterogeneity source in the non-extraction group arose from control group in Wang et al. [21]. The overall effect value $(Z=7.10, P<0.00001)$ suggests that the effect of extraction treatment on tooth length was statistically significant. The total effect of the tooth extraction group was $1.03[0.77,1.30]$, and the total effect value of the non-extractive group was $0.77[0.37,1.18]$. Tooth extraction may have caused more root resorption. The meta-analysis results are shown in Fig. 9.

\section{Tooth length-different interventions}

The study was divided into three subgroups, straight wire, augmented corticotomy-assisted presurgical orthodontics and edgewise technique, based on the orthodontic technique. Subgroup analysis demonstrated that subgroup differences were not statistically significant. Therefore, we speculated different intervention of heterogeneity was less affected. The total effect of the straight wire group was 0.8 [0.52, 1.08], the total effect value of the augmented corticotomy-assisted presurgical orthodontics group was $0.74[0.21,1.27]$ and the total effect of the edgewise group was $0.83[-0.19,1.85]$. The augmented corticotomy-assisted presurgical orthodontics may cause less root resorption. The meta-analysis results are shown in Fig. 10.

\section{Root volume}

Three studies reported changes in root volume using CBCT. The results of meta-analysis revealed that the root volume before and after orthodontic treatment was significantly different $(\mathrm{MD}=23.12,95 \%$ CI $17.88,28.36$ $P<0.00001)$. The root volume was significantly reduced after treatment. The meta-analysis results are shown in Fig. 11.

\section{Discussion}

\section{Summary of main results}

Evidence suggests that orthodontic treatment causes an increased incidence and severity of apical root resorption. Tooth length and root volume were reduced after orthodontic intervention.

\section{Overall completeness and applicability of evidence}

Numerous CBCT studies investigated root resorption before and after orthodontic treatment, but quantitative data of the extraction were only available in 12 articles for a meta-analysis. We chose two major indicators, tooth/root length and root volume, to reflect root resorption. Other indicators that reflect changes were not

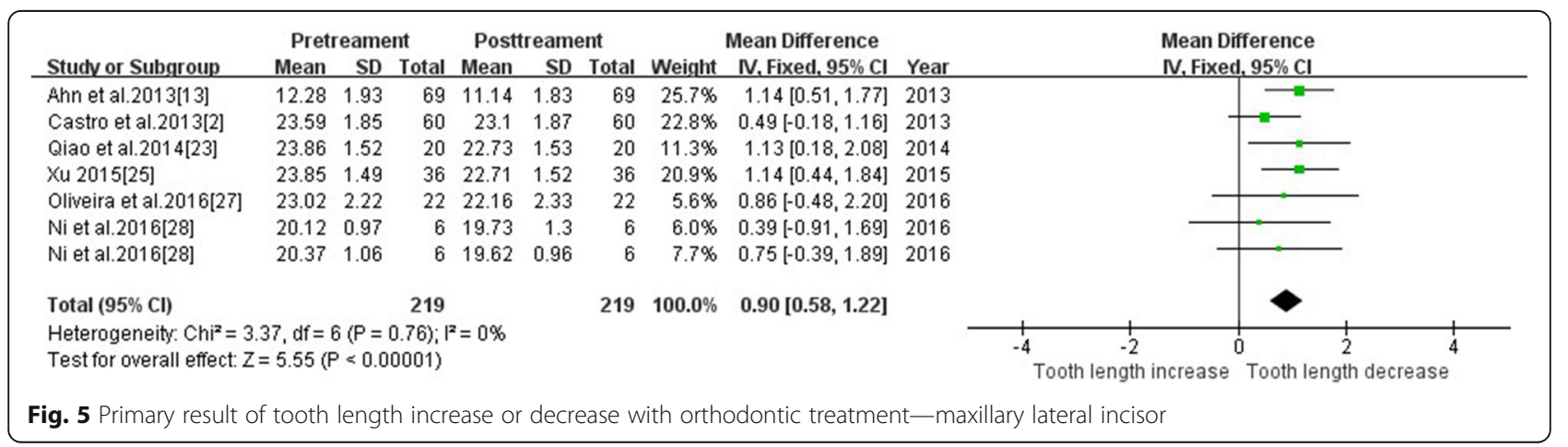




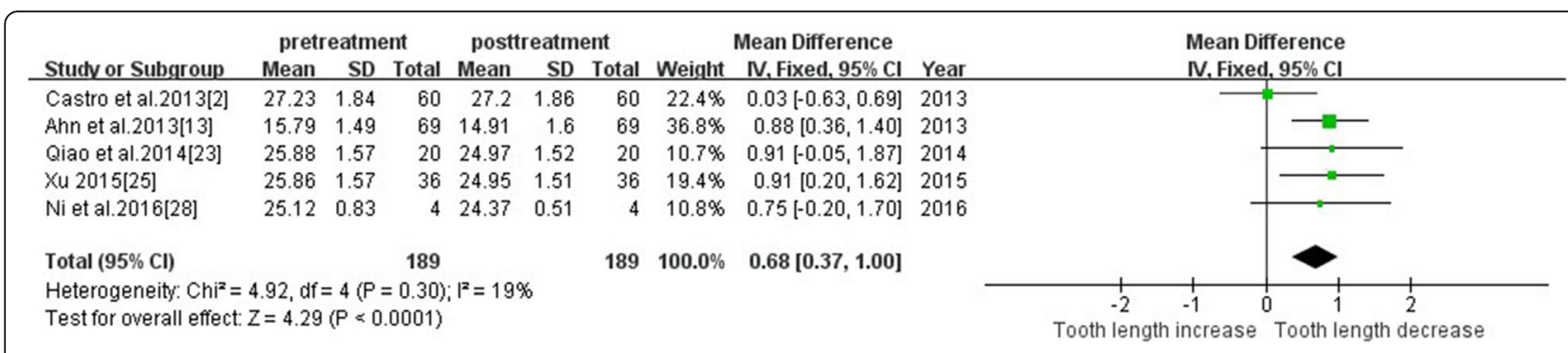

Fig. 6 Primary result of tooth length increase or decrease with orthodontic treatment-maxillary canine

included, and numerical integration and meta-analysis were not performed. Quantitative analysis of other indicators may be performed using numerical analyses to improve the data on this issue.

\section{Quality of the evidence}

Twelve articles were included in this meta-analysis, and all of the studies were non-randomized controlled trials. Randomized controls cannot be used because it is ethically impossible to perform CBCT screenings in patients who have not undergone orthodontic treatment. All studies were self-controlled, which reflects the impact of intervention on these patients more accurately. All patients were diagnosed and measured using $\mathrm{CBCT}$, which excluded the shortcomings of magnification and distortion in 2D image data. All data sources were evaluated more accurately and reproducibly by $\mathrm{CBCT}$, which is the most accurate method of obtaining data in vivo. Methodological evaluation scores from 9 to 15 , and 4 studies received scores that were above or equal to 13 , which were considered as high quality. One study was below 10 and was considered low quality. The remaining studies were of medium quality. The overall quality of the selected literature was good. There were 3 prospective trials, and the remaining trials were retrospective experiments. Prospective experimental evidence will provide more adequate data.

\section{Potential biases in the review process}

The different orthodontic technologies, such as straight wire and edge wise, and corticotomy, incompleteness of some of the reports and lack of quality control in some trials may have contributed to bias in study assessments. We made every attempt to limit bias in the review process by ensuring a comprehensive search for potentially eligible studies. Time limitations prevented the search of additional databases and sources, which may have identified additional published and unpublished studies. There may also be publication bias because of the lack of publication of negative results. We strictly controlled the inclusion of exclusion criteria. There were only two prospective experiments, while others were retrospective studies. There may be biases in sample selection and dropout. The sample size of all studies was relatively small, and only one of the studies calculated the sample size [27].

The age distribution did not completely cover the age of patients with orthodontic treatment, but it covered the span of treatment for most patients. However, there were few samples for adolescent studies, and many patients of orthodontic treatment are adolescents in clinical practice. Therefore, whether the conclusions of this meta-analysis are well suited for adolescent samples must be further studied.

\section{Primary outcome tooth length}

Tooth position Total tooth root length was reduced after orthodontic treatment, and the included studies exhibited a small publication bias. The effect value indicated that the maxillary lateral incisors were the most absorbed, followed by the maxillary central incisors, mandibular anterior teeth and upper canines. Nanekrungsan et al. [8] found that the maxillary lateral incisors

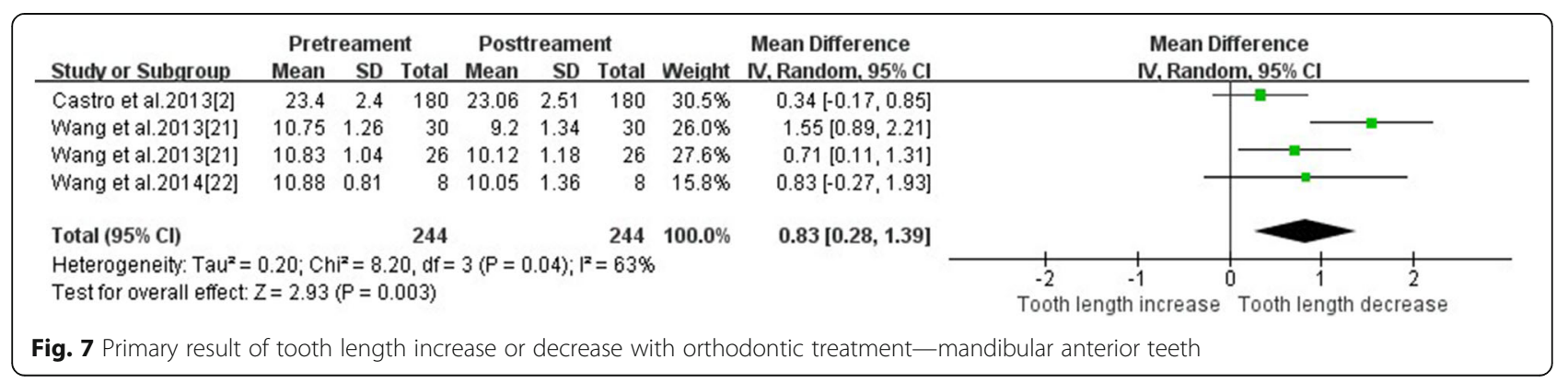




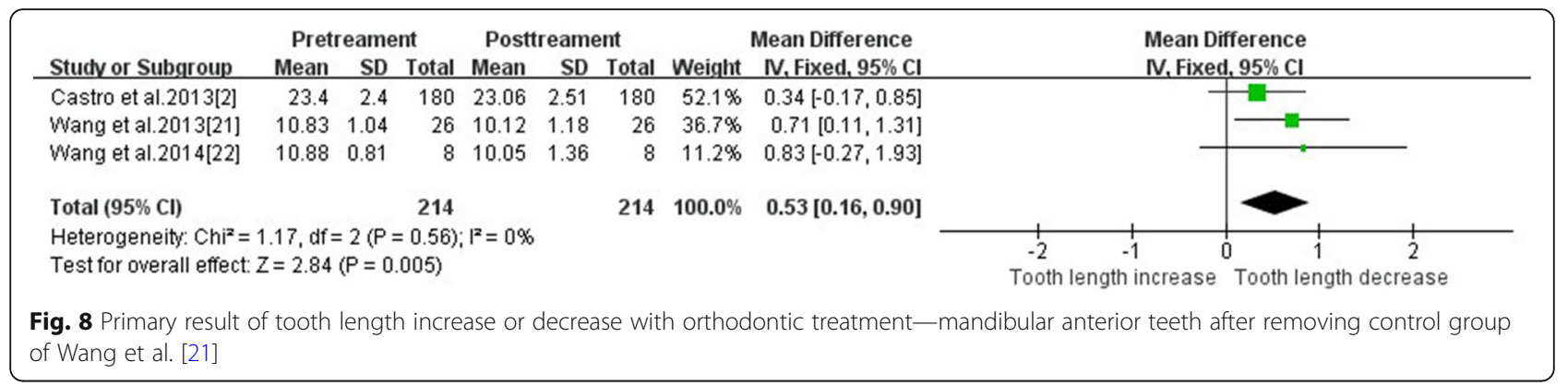

were primarily reduced after treatment. Yu et al. [30] found that the maxillary lateral incisors exhibited greater resorption than maxillary central incisors and canines using CBCT. Kennedy et al. [31] also found that the maxillary lateral incisors were more prone to root resorption than the central incisors. Pejicic et al. [32] found that lateral incisors were primarily affected, and mean values ranged from $0.5 \mathrm{~mm}$ to $3 \mathrm{~mm}$, which is consistent with the conclusions of our study. Previous 2D studies [3, 33, 34] found that maxillary central incisors were the most affected teeth. Sameshima et al. [11] demonstrated that the absorption order was the upper central incisors, the upper lateral incisors, the lower central incisors, and the lower lateral incisors. Jung et al. [35] found that the maxillary central incisors were the most resorbed, with 27\% undergoing greater than $1 \mathrm{~mm}$ of root resorption. Inaccuracies caused by the magnification and overlap of $2 \mathrm{D}$ data, the different types of patient malocclusion, or the different treatment methods may explain the differences in absorption of the anterior teeth.
A meta-analysis of Segal et al. [36] was based on 2D data and demonstrated a strong correlation between root resorption and apical displacement. The mean resorption of upper central incisors was $1.421 \pm 0.448 \mathrm{~mm}$, which was slightly higher than the present study $(\mathrm{MD}=0.84, \mathrm{CI}[0.56,1.12])$. Two-dimensional data may over-estimated root resorption.

The present meta-analysis revealed that the root resorption of the upper central incisors and upper lateral incisors were similar, and it was difficult to determine which tooth was the most affected. The sample of 3D studies was quite small. Therefore, larger 3D sample sizes and more clinical trial evidence are required to supplement and confirm these conclusions.

The heterogeneity of root resorption of the mandibular anterior teeth was high partially because two studies measured the root length and other studies measured tooth length. Removal of the data from control group of Wang et al. [21] reduced the heterogeneity to zero, which suggested that this data was the source of heterogeneity. This group was pre-operative orthodontic of

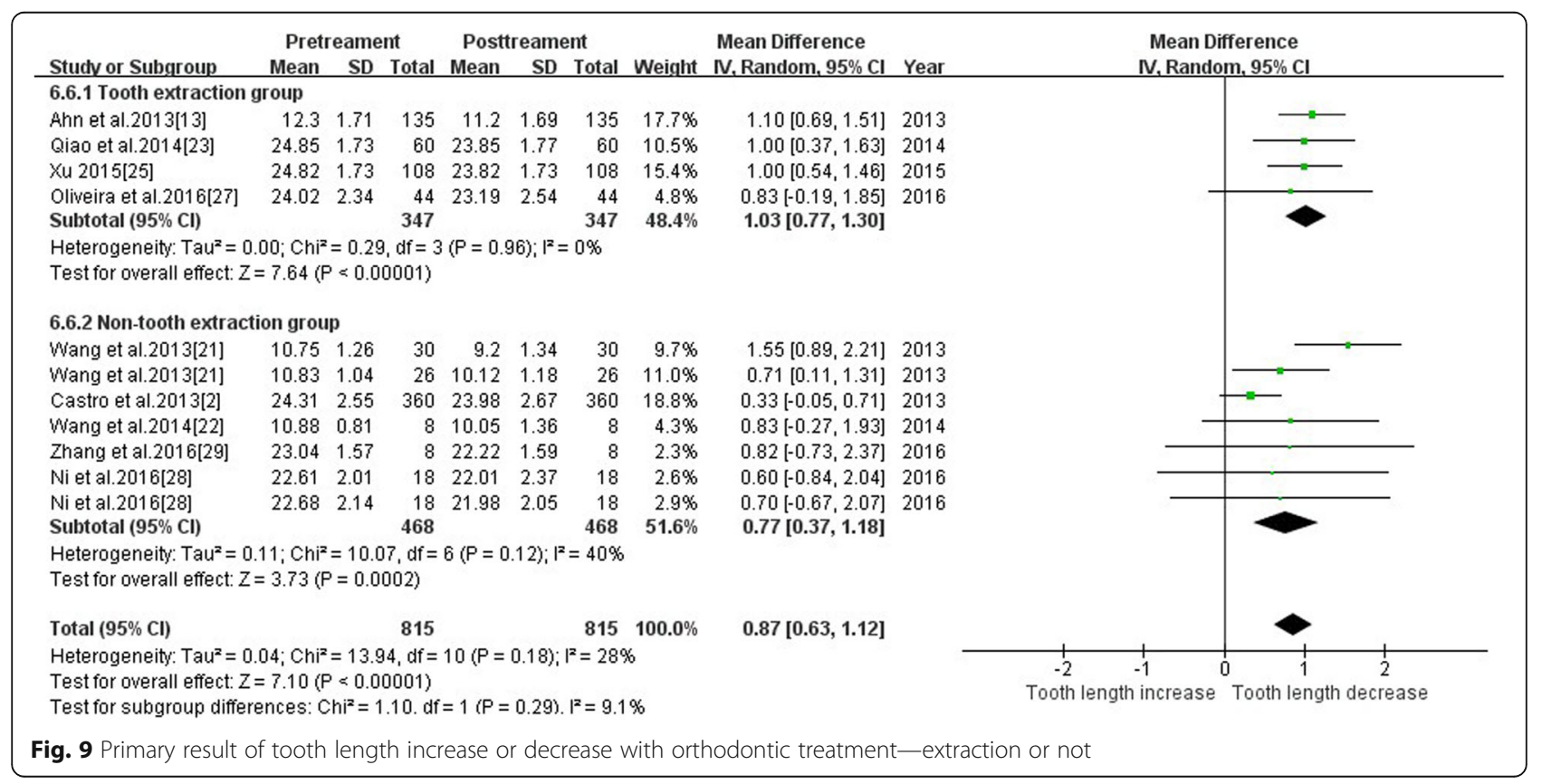




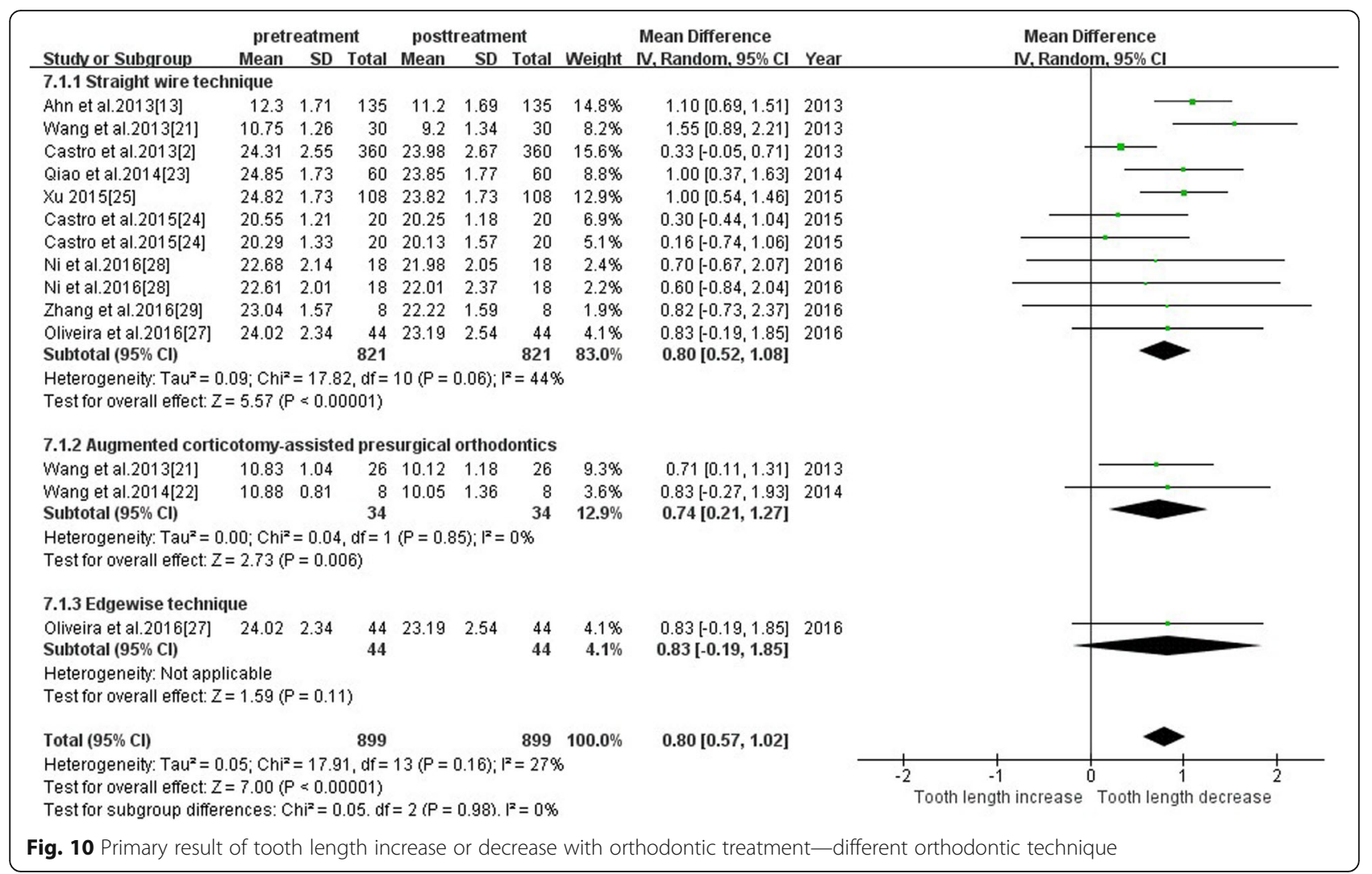

orthognathic surgery patients, which resulted in greater root resorption $(1.55 \pm 0.66 \mathrm{~mm})$. Experimental group was also pre-operatively compensated, but corticotomy was added. A previous study demonstrated that corticotomy reduced the duration of treatment and resulted in lower root resorption compared to traditional methods. Therefore, the value of experimental group may be reduced.

The key of orthodontics prior to orthognathic surgery lies in the anterior teeth for compensation [37]. The root much more easily touches the alveolar bone, which increases the risk of root resorption [38]. Some scholars confirmed that maxillary root resorption is most likely to occur in the patients with bony malocclusion because of the maximum distance of tooth movement, especially the incisors $[39,40]$. Therefore, the data suggest that orthopedic orthodontic treatment of skeletal malocclusion using simple orthodontics will cause more root resorption, regardless of cortical osteotomy intervention.

Extraction vs non-extraction There is controversy about root resorption following extraction and non-extraction methods. The present study was divided into two subgroups: extraction group and non-extraction group. The heterogeneity test found no significant difference between the subgroups. Therefore, the effect of extraction on the heterogeneity is speculative. The overall effect value suggests that the effect of extraction treatment on tooth length was statistically significant. The heterogeneity source of the non-extraction group arose from control group in Wang et al. [21], whose analysis was based on tooth position.

The effect of tooth extraction $(1.03 \pm 0.27)$ on root resorption was greater than that in the non-extraction

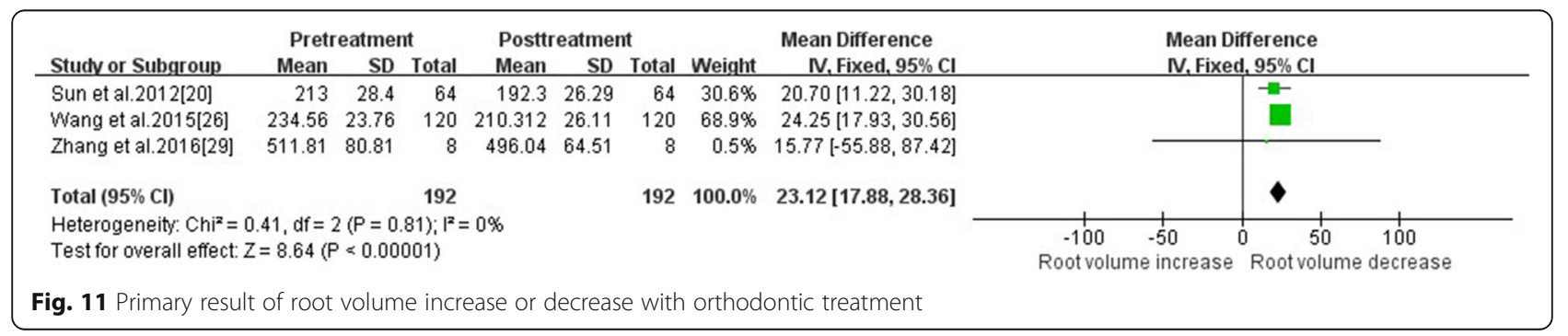


group $(0.77 \pm 0.40)$. Baumrind et al. [41] found no association between tooth extraction and root resorption in a 2D study, which is consistent with the Kaley et al. [42] study. However, Sameshima et al. [11] found that removal of four first premolar teeth resulted in more root resorption than removal of two maxillary premolar teeth or no removal. The incidence of EARR was 3.72 times higher in patients who received extractions than patients without extraction [43]. Sun et al. [44] further confirmed that tooth extraction compared to non-extraction treatment caused more root resorption, which is consistent with the conclusions of the present meta-analysis. Jung et al. [35] found that maxillary central incisors resorption was $0.6 \pm 0.67 \mathrm{~mm}$ in the non-extraction group and $0.98 \pm 0.82 \mathrm{~mm}$ in the extraction group. The mean values are close to the present meta-analysis, but the standard deviation was smaller in our meta-analysis than in his study. In conclusion, the extraction group exhibited greater RR than the non-extraction group. The three-dimensional data were more accurate, and the root resorption that occurred in clinical treatment was not as serious as expected.

Different interventions According to the subgroup analysis of the intervention methods, the intervention was not considered as the main source of heterogeneity in this study. According to the effect value from largest to smallest of root resorption was edgewise, straight wire and augmented corticotomy-assisted presurgical orthodontics. However, there was only one study of edgewise, so more clinical studies were needed for the comparison between edgewise and other orthodontic techniques. The corticotomy group had a slightly lower root resorption than the straight wire group, suggesting that corticotomy may also reduce tooth root resorption in addition to accelerating tooth movement [45].

\section{Primary outcome tooth volume}

Root resorption is not just a two-dimensional change in length, it actually occurs in three dimensions, including on the buccal-lingual and mesial-distal sides. Therefore, the volume index is more realistic than the length index, which reflects the root resorption accurately. All three studies [20, 26, 29] focused on the maxillary and mandibular incisors and were consistent with no heterogeneity in the length index.

\section{Factors affecting root resorption}

Treatment duration Clinical studies demonstrated that a long course of treatment may cause more serious root resorption [41, 46-48]. Therefore, clinical orthodontists should avoid prolonged orthodontic treatment. However, if the patient has had root resorption or root resorption prior to treatment, orthodontic treatment will increase the degree and speed of root resorption, which causes severe root resorption [46]. However, some studies reported no correlation between treatment duration and apical root loss [34, 49]. One possible reason is that patients prolonged the treatment because of untimely referral. The limited periods of activation during the prolonged referral period in a lighter force system may also explain this difference. Harry et al. [50] suggested that the stress duration is the more serious reason than the magnitude of force. Segal et al.'s meta-analysis based on 2D data demonstrated a strong correlation between root resorption and duration [36].

Treatment duration is a risk factor of root resorption, but it is also correlated with it. We included data before and after comprehensive orthodontic treatment rather than topical or stage treatment to exclude changes in tooth length that occurred only after months of adduction or depression. Normal orthodontic treatment of a general course is $2-3$ years, and stage data may not reflect the complete response to an entire treatment. The present study included before and after treatment data, which reduced the bias to some extent. These results provide the best available evidence for clinical decisions to minimize the risk and severity of apical root resorption. Therefore, clinicians should be very careful when moving anterior teeth over a long distance and a long time.

\section{Limitations}

1. There were many confounding factors, such as tooth movement distance, magnitude of force, alveolar shape and technique. There was no regression analysis of age, gender or other risk factors. Original studies did not meet consistent inclusion and exclusion criteria and provided limited information about age and could not be compared quantitatively. We hope that more unified reference planes and measurement methods may be used in future quantitative analyses.

2. Only non-randomized controlled trials (self-controlled trials) were included because of the lack of a large number of related RCT experiments due to limited conditions.

3. Most of the included trials (9 papers) resulted in changes in the length of the tooth, and root resorption was a three-dimensional change, not only in two dimensions. However, only three studies included volume changes.

4. Most of the research focused on the upper and lower anterior teeth, and root resorption of the upper and lower posterior teeth was less studied. Therefore, total dentition root resorption severity and impact factors require further experiments to verify. 


\section{Clinical significance}

It is necessary to inform patients of the risk of root resorption prior to orthodontic treatment. Significant shortening of the root length will lead to inappropriate crown-root ratios and adjacency to the periodontal tissue. Apical resorption greater than $3 \mathrm{~mm}$ is equivalent to $1 \mathrm{~mm}$ of bone loss, which will accelerate the periodontal disease process. The treatment program must be re-evaluated if serious root resorption is found. Future experiments should be based on a reasonable sample size and the implementation of the entire orthodontic process to ensure the effect value.

The above meta-analysis demonstrated that the average value of root resorption was approximately $1 \mathrm{~mm}$, and the upper limit did not exceed $2 \mathrm{~mm}$. Sharpe's grading standards indicated that the first grade was slightly blunt $(1-2 \mathrm{~mm})$ [51]. The results were grade 1 . Malmgren's rating standard indicates that level 1 is irregular root contour and level 2 is root resorption apically amounting to less than $2 \mathrm{~mm}$ (minor resorption) [40]. The most serious case did not exceed 2 degrees, and it was a mild absorption.

\section{Conclusions}

The following conclusions are drawn based on the existing research:

1. Evidence suggests that orthodontic treatment increased the incidence and severity of apical root resorption. Tooth length and root volume were reduced after orthodontic intervention, but these changes were in a clinically acceptable range.

2. Different tooth positions exhibited different degrees of absorption, and the sequence of RR from heaviest to lightest was maxillary lateral incisors, maxillary central incisors, mandibular anterior teeth, and maxillary canines.

3. Tooth extraction may result in more root resorption than non-extraction.

4. Most of the patients measured using CBCT exhibited root resorption within the clinically acceptable range. The RR value of CBCT was lower than the $2 \mathrm{D}$ data.

However, more methods are needed to provide more reliable evidence for clinical trials based on CBCT data. Experimental studies on treatment, the distance and angle of tooth movement, and correction techniques may provide more clinical guidance for orthodontic treatment of $R R$ reduction.

\section{Abbreviations}

2D: Two-dimensional; 3D: Three-dimensional; CBCT: Cone beam computed tomography; CNKI: China National Knowledge Infrastructure; EARR: External apical root resorption; m: Month; MINORS: Methodological index for nonrandomized studies; PRISMA: Preferred Reporting Items for Systematic
Reviews and Meta Analyses; RL: Root length; RR: Root resorption; TL: Tooth length; TV: Tooth volume

Availability of data and materials

All data generated or analyzed during this study are included in this published article.

\section{Authors' contributions}

YD and YS were responsible for study selection, quality assessment, data extraction and data synthesis. YD drafted the manuscript. TX participated in the research design and revision of the manuscript. All authors read and approved the final manuscript.

Ethics approval and consent to participate

Not applicable.

\section{Consent for publication}

Not applicable.

\section{Competing interests}

The authors declare that they have no competing interests.

\section{Publisher's Note}

Springer Nature remains neutral with regard to jurisdictional claims in published maps and institutional affiliations.

Received: 31 January 2018 Accepted: 17 June 2018

Published online: 27 June 2018

References

1. Killiany DM. Root resorption caused by orthodontic treatment: an evidencebased review of literature. Semin Orthod. 1999:5:128-33.

2. Castro IO, Alencar AH, Valladaresneto J, Estrela C. Apical root resorption due to orthodontic treatment detected by cone beam computed tomography. Angle Orthod. 2013;83:196-203.

3. Jiang RP, Mcdonald JP, Fu MK. Root resorption before and after orthodontic treatment: a clinical study of contributory factors. Eur J Orthod. 2010;32: 693-7.

4. Weltman B, Vig KW, Fields HW, Shanker S, Kaizar EE. Root resorption associated with orthodontic tooth movement: a systematic review. Am J Orthod Dentofac Orthop. 2010;137:462-76.

5. Martins DR, Tibola D, Janson G, Maria FR. Effects of intrusion combined with anterior retraction on apical root resorption. Eur J Orthod. 2012:34:170-5.

6. Picanço GV, de Freitas KM, Cançado RH, Valarelli FP, Picanço PR, Feijão CP. Predisposing factors to severe external root resorption associated to orthodontic treatment. Dental Press J Orthod. 2013;18:110-20.

7. Acar A, Canyürek U, Kocaaga M, Erverdi N. Continuous vs. discontinuous force application and root resorption. Angle Orthod. 1999;69:159-63.

8. Nanekrungsan K, Patanaporn V, Janhom A, Korwanich N. External apical root resorption in maxillary incisors in orthodontic patients: associated factors and radiographic evaluation. Imaging Sci Dent. 2012:42:147-54.

9. Parker RJ, Harris EF. Directions of orthodontic tooth movements associated with external apical root resorption of the maxillary central incisor. Am J Orthod Dentofac Orthop. 1998:114:677-83.

10. Peck JL, Sameshima GT, Miller A, Worth P, Hatcher DC. Mesiodistal root angulation using panoramic and cone beam CT. Angle Orthod. 2007;77:206-13.

11. Sameshima GT, Asgarifar KO. Assessment of root resorption and root shape: periapical vs panoramic films. Angle Orthod. 2001:71:185-9.

12. Baumrind $S$, Miller $D$, Molthen $R$. The reliability of head film measurements. 3 Tracing superimposition. Am J Orthod. 1976;70:617-44.

13. Ahn HW, Moon SC, Baek SH. Morphometric evaluation of changes in the alveolar bone and roots of the maxillary anterior teeth before and after en masse retraction using cone-beam computed tomography. Angle Orthod. 2013;83:212-21.

14. Dudic A, Giannopoulou C, Leuzinger M, Kiliaridis S. Detection of apical root resorption after orthodontic treatment by using panoramic radiography and cone-beam computed tomography of super-high resolution. Am J Orthod Dentofac Orthop. 2009;135:434-7.

15. Durack C, Patel S, Davies J, Wilson R, Mannocci F. Diagnostic accuracy of small volume cone beam computed tomography and intraoral periapical 
radiography for the detection of simulated external inflammatory root resorption. Int Endod J. 2011;44:136-47.

16. Estrela C, Bueno MR, Leles CR, Azevedo B, Azevedo JR. Accuracy of cone beam computed tomography and panoramic and periapical radiography for detection of apical periodontitis. J Endod. 2008;34:273-9.

17. Wang Y, He S, Guo Y, Wang S, Chen S. Accuracy of volumetric measurement of simulated root resorption lacunas based on cone beam computed tomography. Orthod Craniofac Res. 2013;16:169-76.

18. Roscoe MG, Meira JB, Cattaneo PM. Association of orthodontic force system and root resorption: a systematic review. Am J Orthod Dentofac Orthop. 2015;147:610-26.

19. Liedke GS, Da SH, Da SH, Dutra V, de Figueiredo JA. Influence of voxel size in the diagnostic ability of cone beam tomography to evaluate simulated external root resorption. J Endod. 2009;35:233-5.

20. Sun BY, Wang L, Deng RX, Ding Y. Comparative evaluation of root resorption in mandibular incisors following the treatment of adults with skeletal class III. Prog Mod Biomed. 2012:12:1098-100.

21. Wang B, Shen G, Fang B, Yu H, Wu Y. Augmented corticotomy-assisted presurgical orthodontics of class III malocclusions: a cephalometric and conebeam computed tomography study. J Craniofac Surg. 2013;24:1886-90.

22. Wang B, Shen G, Fang B, Yu H, Wu Y, Sun L. Augmented corticotomyassisted surgical orthodontics decompensates lower incisors in class III malocclusion patients. J Oral Maxillofac Surg. 2014;72:596-602.

23. Qiao YQ, Zhu FJ, Cui SX. Study of CBCT for root resorption of the anterior teeth of maxillary during adult orthodontic treatment. Med Innov China. 2014;11:006-9.

24. Castro I, Valladares-Neto J, Estrela C. Contribution of cone beam computed tomography to the detection of apical root resorption after orthodontic treatment in root-filled and vital teeth. Angle Orthod. 2015;85:771-6.

25. Xu SD. Explore the evaluation of adult orthodontic treatment of root resorption with CBCT. Gen J Stomatol. 2015;2:98-9.

26. Wang $F$, Wang JG, Zhang XZ. Examining incisor root resorption using CBCT after orthodontic treatment for adults with skeletal class III malocclusion. Tianjin Med J. 2015;43:390-3.

27. Oliveira TM, Claudino LV, Mattos CT, Sant'Anna EF. Maxillary dentoalveolar assessment following retraction of maxillary incisors: a preliminary study. Dental Press J Orthod. 2016;21:82-9.

28. Ni M, Lei Y, Chen WJ, Wu GR. Cone beam computed tomography study on the apical root resorption after orthodontic treatment in root-filled teeth. Stomatologie. 2016;36:233-6.

29. Zhang RF, Wang HM, Bai YX, Li S. Effects of orthodontic force on upper central incisor's developing roots. Beijing J Stomatol. 2016;24:335-7.

30. Yu JH, Shu KW, Tsai MT, Hsu JT, Chang HW, Tung KL. A cone-beam computed tomography study of orthodontic apical root resorption. J Dent Sci. 2013;8:74-9.

31. Kennedy DB, Joondeph DR, Osterberg SK, Little RM. The effect of extraction and orthodontic treatment on dentoalveolar support. Am J Orthod. 1983;84:183-90

32. Pejicic A, Bertl M, Čelar A. Extent and prognosis of apical root resorption due to orthodontic treatment. Int I Stomat Occ Med. 2012;5:147-54.

33. Ousehal L, Lazrak L, Essmaali FE, Ngom PI. Apical root resorption in patients wearing orthodontic appliances. Odontostomatol Trop. 2012;35:12-8.

34. Makedonas D, Lund H, Hansen K. Root resorption diagnosed with cone beam computed tomography after 6 months and at the end of orthodontic treatment with fixed appliances. Angle Orthod. 2013;83:389-93.

35. Jung $\mathrm{YH}$, Cho BH. External root resorption after orthodontic treatment: a study of contributing factors. Imaging Sci Dent. 2011;41:17-21.

36. Segal GR, Schiffman PH, Tuncay OC. Meta analysis of the treatment-related factors of external apical root resorption. Orthod Craniofac Res. 2004:7:71-8.

37. Worms FW, Isaacson RJ, Speidel TM. Surgical orthodontic treatment planning: profile analysis and mandibular surgery. Angle Orthod. 1976:46:1-25.

38. Vardimon A, Oren E, Ben-Bassat Y. Cortical bone remodeling/tooth movement ratio during maxillary incisor retraction with tip versus torque movements. Am J Orthod Dentofac Orthop. 1998;114:520-9.

39. Horiuchi A, Hotokezaka H, Kobayashi K. Correlation between cortical plate proximity and apical root resorption. Am J Orthod Dentofac Orthop. 1998; 114:311-8.

40. Levander $\mathrm{E}$, Malmgren O. Evaluation of the risk of root resorption during orthodontic treatment: a study of upper incisors. Eur J Orthod. 1988;10:30-8.

41. Baumrind S, Korn EL, Boyd RL. Apical root resorption in orthodontically treated adults. Am J Orthod Dentofac Orthop. 1996;110:311-20.
42. Kaley J, Phillips C. Factors related to root resorption in edgewise practice. Angle Orthod. 1991;61:125-32.

43. Mcnab S, Battistutta D, Taverne A, Symons AL. External apical root resorption following orthodontic treatment. Angle Orthod. 2000;70:227-32.

44. Sun J, Wu YY, Wei D, Li W. Study of effect of different premolar extraction models on the incisor root resorption using panoramic radiography and cone beam computed tomography. Stomatologie. 2014;34:608-10.

45. Faedda GL, Baldessarini RJ. Treatment-emergent mania in pediatric bipolar disorder: a retrospective case review. J Affect Disord. 2004;82:149-58.

46. Brezniak N, Wasserstein A. Root resorption after orthodontic treatment: part 1. Literature review. Am J Orthod Dentofac Orthop. 1993:103:138-46.

47. Mohandesan $\mathrm{H}$, Ravanmehr $\mathrm{H}$, Valaei N. A radiographic analysis of external apical root resorption of maxillary incisors during active orthodontic treatment. Eur J Orthod. 2007;29:134-9.

48. Brin I, Tulloch JF, Koroluk L, Philips C. External apical root resorption in class II malocclusion: a retrospective review of 1- versus 2-phase treatment. Am J Orthod Dentofac Orthop. 2003;124:151-6.

49. Jiang F, Chen J, Kula K, Gu H, Du Y, Eckert G. Root resorptions associated with canine retraction treatment. Am J Orthod Dentofac Orthop. 2017:152:348-54.

50. Harry MR, Sims MR. Root resorption in bicuspid intrusion. A scanning electron microscope study. Angle Orthod. 1982;52:235-58.

51. Sharpe W, Reed B, Subtelny JD, Polson A. Orthodontic relapse, apical root resorption, and crestal alveolar bone levels. Am J Orthod Dentofac Orthop. 1987;91:252-8.

\section{Ready to submit your research? Choose BMC and benefit from:}

- fast, convenient online submission

- thorough peer review by experienced researchers in your field

- rapid publication on acceptance

- support for research data, including large and complex data types

- gold Open Access which fosters wider collaboration and increased citations

- maximum visibility for your research: over $100 \mathrm{M}$ website views per year

At BMC, research is always in progress.

Learn more biomedcentral.com/submissions 